\title{
BOLLYWOOD DREAMS? \\ THE RISE OF THE ASIAN MELA AS A GLOBAL \\ CULTURAL PHENOMENON
}

\author{
Melanie Smith ANd Elizabeth CARnegie
}

Public History ReVIeW Vol 12, 2006, PP1-11

\begin{abstract}
$\mathrm{T}$ he term 'Mela' is derived from a Sanskrit word meaning 'gathering' and is used to describe a range of community events in the Asian sub-continent. The cultural activities included in Mela are many and varied incorporating, amongst others, music, dance, fashion, food and sometimes film. In recent years, Mela has become an increasingly prominent feature within the cultural calendar of many Western European countries particularly in Britain. Melas have gradually developed from small-scale community-based events in India to national celebrations of Diasporic cultures in Western countries. Like Caribbean Carnivals, Melas have come to symbolise all that is 'colourful' about Diaspora, transforming ethnicity into a cultural showcase for growing numbers of white and tourist audiences. Whilst this is perhaps an ineluctable consequence of globalisation questions should be raised about the appropriation of such cultural forms and the power relationships inherent within their development.

Recent government agendas claim to promote cultural diversity but how far is the support tokenistic rather than being a genuine attempt to further social integration? Cultural purists might well balk at the apparent hybridisation of cultural and artistic expression and performance within the context of Mela. This issue will be exemplified in the case study of the Edinburgh Mela in the latter part of the article. The preservation of artistic integrity is arguably paramount in the conceptualisation of Mela but how far are the changing composition and demands of audiences dictating the nature of programming and performance? It might well be argued that the Melange of cultural forms that now constitute Mela are representative of the multifarious nature of Diasporic cultures and identities. The complexity of such issues, however, needs further exploration.
\end{abstract}

\section{Globalisation: A Bollywood DReAm?}

In recent years, there has been a resurgence of interest in Indian culture in Britain comparable, perhaps, to that of the time when the Beatles were hanging out with the Maharishi and playing sitar with Ravi Shankar in the 1960s. Chicken Tikka Masala is often quoted as being the most popular food in Britain. Hybridised 
cuisine abounds, including the apparent development of a 'Balti pie' in the north of England. The musical Bombay Dreams has attracted large audiences in the West End in London and many people are clamouring to attend Bollywood dance classes. Cinema has afforded a proliferation of films depicting both the attractions and complexities of Asian cultures. For example, East is East, Monsoon Wedding and Bend it Like Beckham all challenged traditions which do not always sit comfortably with modern day or second generation Indians. Strains of the gritty folk music of rural India have started to pervade mainstream pop music in the form of Bhangra. The attraction of Westerners to yoga and holistic therapies such as Ayurveda - is becoming more common, popularised mainly by star yogis such as Madonna, Sting and Geri Halliwell.

It is therefore not surprising that Asian Mela festivals appear to be growing in popularity and seem to symbolise the emergence of a new Britain where traditions and hybridised cultural forms inevitably intermingle and collide. This is inherently problematic, however, as the original concept of Mela was based predominantly on traditional and folk cultures rather than popular or global cultural forms. Whilst the latter might be appealing to younger audiences there are concerns amongst older generations that Asian culture is being diluted or subsumed.

Ferguson describes how globalisation of the media has led to the fragmentation of cultural representation which is then reconstituted and usually referred to as cultural hybridity. ${ }^{1}$ The Parekh Report suggests that the 'process of mixing and hybridisation will increasingly be the norm where rapid change and globalisation have made all identities potentially unstable'. ${ }^{2}$ Weeks argues that threatened commmunities 'construct out of this a community of identity which provides a strong sense of resistance and empowerment'. ${ }^{3}$ But Flusty reminds us that 'all cultures are hybrids of other cultures' influences and always have been. Thus hybridity is neither new or distinct, but an omnipresent underpinning of cultural formation' ${ }^{4}$ It is, of course, misguided to refer to Asians as a single homogenous group and critical distinctions should be made between Bangladeshis, Gujaratis, Pakistanis and Punjabis as well as between South Asians, East African Asians and Chinese and between Hindus, Muslims and Sikhs. The role that different religions and caste have traditionally played in Asian societies cannot be underestimated.

Relationships between these groups in the democracy of 'Mother India' have not always been harmonious thus the achievement of integration within Britain is complicated further. The aforementioned Parekh report also notes the internal diversity in Asian communities where there are deep divisions between generations. Parents and children are often in disagreement about the dangers of assimilation. The report suggests that there is too much emphasis on separating 'ethnic' traditions from 'western' canon and on conserving the past rather than promoting new creativity in the present. Similarly, Baumann describes how cultural distinctiveness within Asian communities is often defined by parents in terms of their own pre-emigration traditions and heritages. ${ }^{5}$ 
Brah suggests that the notion of Diaspora in Britain was always discussed along a 'majority/minority' axis but that this is no longer appropriate: 'Diaspora space as a conceptual category is "inhabited" not only by those who have migrated and their descendants but equally by those who are constructed and represented as indigenous'. ${ }^{6}$ Thus the children of first generation immigrants have become indigenised and are often searching for a new identity within the context of multi-cultural Britain. Although Bauman questions whether individuals, and in particular those deemed weak and powerless within wider society, have the freedom to change their identity. ${ }^{7}$ Back notes that urban cultures in particular tend to be 'promiscuous' in their endeavour to continuously re-make and invent traditions in the present. ${ }^{8}$ Baumann's work in London demonstrated the emergence of a new Asian culture based on identity construction. ${ }^{9}$ Many young Asians were searching for the kind of 'roots' feeling that reggae had given to African Caribbeans. For a time, the reductionist term 'Black' in Britain served to subsume Asian cultures, with many young Asians emulating Black kids - recently parodied by the comedian Ali G - while searching for an identity of their own. Baumann suggests that many teenagers wish to see the emergence of an Asian culture which transcends differences of religion, caste or regional affiliation. ${ }^{10}$ As the case study of the Edinburgh Mela will highlight, generational difference are equally apparent within all cultures and encouraging engagement with 'traditional artforms' is viewed as a key issue for funding bodies and in particular local government.

Bhangra music appears to have become the cultural form which many young Asians have adopted to express a sense of roots and identity. ${ }^{11}$ The recent success of Panjabi MC is a good indication of the rising popularity of this form of music within the mainstream industry especially given the growing propensity of artists such as Britney Spears, Craig David and Ricky Martin to infuse their own music with Bhangra influences. Chaudhary is cynical about this development, suggesting that hybridisation represents the dilution of a traditional art form: 'Modern British Bhangra sadly lacks the cutting edge and social realism of its more authentic Indian counterpart and indeed the great doyens of bhangra music would most probably be hard pushed to recognise it'. ${ }^{12}$ His viewpoint, however, arguably reflects that of the Asian parent harking back to pre-emigration traditions. The modern Mela perhaps needs to be progressive and dynamic in its cultural programing to attract young Asian audiences. Mela directors interviewed suggested that many young people would not attend Mela if it simply reflected traditional cultures.

\section{Melas AND the Showcasing of Ethnic Cultures}

Morley suggests that World Music Festivals have helped to undermine the cultural hegemony of white 'Britpop' and allowed commercial marketing opportunities for non-white, non-Western music. ${ }^{13}$ It could perhaps be argued that Melas serve a similar function although the commercial element is perhaps of less importance than the community aspect. 
Khan's work on ethnic minority arts suggested that ethnic contributions enhanced the UK's cultural provision considerably. By showcasing their culture, minority groups were able to assert their identity. ${ }^{14}$ Carlson similarly suggests that cultural performance can allow traditionally marginalised groups to explore relationships between self and society as well as issues relating to objectification, exclusion and identity. ${ }^{15}$ Candida-Smith's work also sees performance as a memory trigger which is linked to memories of traditional ways of life. ${ }^{16}$ This might be an important point to note in the case of Diasporic cultures where there is often a strong sense of both 'over here' and 'over there' - that is, 'back home'. ${ }^{17}$ Jermyn and Desai optimistically state that barriers to ethnic participation in the arts are gradually being removed. ${ }^{18}$ But Mowitt is more cynical, suggesting that there is a great deal of tokenism in Government support for ethnic minorities: 'In a global white world, a little local color goes a long way'. ${ }^{19}$ Lippard outlines the key problem with discourse in ethnic art, in that it tends to be about the Other rather than by the Other. ${ }^{20}$ Appropriation of ethnic cultural forms is not uncommon in the programing, interpretation and representation of art. In addition, audience development for ethnic and minority events can be contentious with claims that Caribbean Carnivals and similar events are becoming 'whitewashed' or overtouristed. ${ }^{21}$

It is significant to note that many directors interviewed were keen to drop the term 'Asian' from Mela in order to suggest that it is an inclusive celebration. In the case of the Rochdale Mega-Mela, African drumming is included as an activity. In comparison to African Caribbean carnivals, it could be argued that Melas are less overtly political in their origins. Whereas carnivals were generally born out of the oppressive context of imperialism, colonisation and slavery, ${ }^{22}$ Melas appear to be predominantly celebrations of community cultures. It would, however, be naive in the extreme to suggest that Melas are de-politicised events. There are concerns about appropriation, especially in areas where Local Authorities are keen to hijack Melas in order to add local colour to their promotion. Problems of racism in some parts of Britain have not been eradicated. In fact the rise of the British National Party suggests that the opposite is true. Some Mela directors fear for the future of their Mela in areas where ethnic tensions are rife. In some cases, Mela directors are white rather than Asian which might suggest further appropriation. From discussions with these directors, however, it is clear that they were often invited to take the position, especially in cases where there were internal political tensions.

Audience development is problematic. As mentioned earlier, many directors are struggling to attract young Asians to their Melas as they are perceived to be overly traditional. The desire appears to be to retain an Asian focus but within a world context, therefore hybridisation which reflects national and global influences predominates. The Mela of the future will no doubt celebrate the rich traditions of Asia whilst reflecting the dynamic nature of British Asian culture. There are clearly some concerns about non-target audiences such as white tourists. At present, white people constitute fifty per cent of audiences. But the general consensus of 
directors is that Melas should be more widely promoted. This clearly makes more commercial sense though care must be taken not to alienate core Asian audiences in the process.

\section{CASe Study: The EdinbuRgh Mela}

The Edinburgh Mela celebrated its tenth year in 2004 and in 2003 extended to three days to include Friday, Saturday and Sunday. A record 40,000 visitors attended that year. This was an increase of 10,000 on 2002 figures.

Professionally staffed and funded from the onset, it has a Chief Executive and Administration Manger on half-time contracts, a marketing manager on a 0.4 contract and has a number of short term staff including production manager, administration and site staff and hosts creative residencies including in 2003-4 a Chinese musician on a half-time contract. Professionalism was seen as key to developing the reputation of the Edinburgh Mela and crucial in attracting sponsorship. The 2003 Edinburgh Mela was sponsored by O2 with the combined strength of the European Mela Network helping to raise the profile of Melas in general.

The Edinburgh Mela currently has a board of eleven people of which two are white: the Lord Provost of Edinburgh and Professor Maggie Kinlop, Queen Margaret University College. Nine are from South Asia comprising five men and four women including local entrepreneur Mrs Unis. Another board member Mohammed Sahaffi was awarded an MBE in the 2002-3 honours list for his services to the arts in Scotland. The Chief Executive, Alan Tweedie, is white having been 'heavily persuaded' by some of the leaders of the community to chair the board from the onset as they had witnessed other potential ventures fail as a consequence of internal politics. Additionally, there are three consultative forums held throughout the year with invited audiences from 120 local organisations resulting in some twenty-eight representatives from other communities within the city.

According to Tweedie the Edinburgh version has 'rejected the concept of multi-culturalisation in favour of inter-culturalisation', in a bid to create a genuinely and generally inclusive event intended to become an established part of Edinburgh's Festivals. ${ }^{23}$ Positioned within the summer festival season, over the last weekend of the International Festival, the Mela inevitably draws a mixed audience of locals and tourists. The decision to cite the Mela within the festival season was taken for a number of reasons.

The Edinburgh Mela was based on the Bradford model which is part of the wider Bradford Festival and was viewed by the organising committee in Edinburgh to be a model which worked well in attracting audiences although as previously discussed there have been criticisms levied at local government attempts to hijack the Bradford Mela for political purposes. From the onset the Edinburgh Mela has received local government funding but it was argued that the later in the year an event is held the more chance it has of obtaining money from other grant award bodies. Of key concern to an event, which traditionally happens 
out of doors, is the Scottish weather. Tracking of weather favoured that particular weekend minimising the risk of a wash out. It was also suggested by Tweedie that as the tourist season is coming to a close towards the end of August people who are tied up with working in the hospitality industries are able to free up time to participate in the Mela. ${ }^{24}$

It also seems likely that weather and funding considerations apart, the decision to position it during the festival would both ensure an audience for events and give some sense of parity of esteem to the Mela as it would happen in tandem with prestigious festival activities. It would also benefit from the Edinburgh Festival's publicity machine.

\section{Aims of the Edinburgh Mela}

A large percentage of the visitors to the Edinburgh Mela are white, although Tweedie argues that some international audiences, for example Brazilians, would have more in common with the Mela than some local Moslem audiences: Brazil has a long tradition of carnival and local Moslems may not come from such a culture of openness in terms of display. ${ }^{25} \mathrm{He}$ acknowledges twin concerns about audiences and indeed Mela participants: 'If the majority of attendees are white then it is no longer a Mela... [yet] a Mela which represents some monoculture wouldn't be a Mela. ${ }^{26}$ The decision to create a Mela in Edinburgh, which has now grown to Scotland's largest Mela, outpacing the Glasgow equivalent, grew from the organisers belief that despite there being fifteen key festivals in Edinburgh with forty smaller ones throughout the year little was being done within the city to celebrate and reflect the arts and culture of the world. Tweedie argues that Edinburgh's cultural activities, and in particular those of the official International Festival, are 'heavily dependant on the much more developed world, especially Europe and North America... at that time what was termed the third world was largely excluded because of the vision of the people that controlled the International festival'. ${ }^{27}$ Although international groups visit the city to participate in festival events these are not necessarily attended by local audiences and rarely create a forum for multi-ethnic groups throughout the year. Accusations of elitism about the cultural product that is the Edinburgh International Festival are not new and similar arguments reflect class issues within the city. ${ }^{28}$

The Edinburgh Mela sought to redress this imbalance through producing a program of events which addressed the following key concerns:

- Clear vision in the initial group that was internationalist but Scottish, about quality, innovation and creating magic

- Melas could enhance the self respect of all people in minority communities but especially young people

- There is the potential in Melas for inclusion allowing all generations to come out and enjoy themselves together 
- Awareness through living in a culturally diverse Scotland that new approaches were required to bring about recognition and celebration of that diversity

- Growing awareness of the hybrid nature of south Asian culture and the diversity of south Asian culture in a changing UK and world context

- Methodology from the start that stressed networking, partnership and collaboration and that built in opportunities for members of the community to achieve both group and individual development

- Growing aspiration of achieving recognition as a major festival in its own right and becoming a significant player in the local, regional, national and international infrastructures and

- Working together across cultures towards racial equality and harmony. ${ }^{29}$

\section{SCOTLAND IN THE MELA OR THE MELA IN SCOTLAND?}

The Edinburgh Mela is held within the bleak cultural landscape of Pilrig Park, an inner city green space in a working-class suburb of Edinburgh, and has always been about presentation and not just about product. Much thought goes into set dressing and adding colour to create a sense of the Diaspora which serves as the venue for the Mela. This partly recalls Mowitt's observation that a little local colour goes a long way. ${ }^{30}$ Tweedie argues that Indian Melas 'don't need to concern themselves with production, as there is so much wealth around them. But here if we want to have a creative environment which involves cultural Diasporas we have to be creative about how we do it'. ${ }^{31}$

The decision to hold the Mela in a fixed venue, geographically close to where many of Edinburgh's South Asian population work and live, was deemed important to creating a sense of ownership of the space and continuity from one year to the next. This is by no means a belief held uniformly by the board and a small minority would like the Mela to move away from its community roots and to develop a more populace approach which reflects the growing interest in popular and hybridised culture. When a similar suggestion was made to move the Notting Hill Carnival in London to Hyde Park it created something of a furore from local residents. The connections to a geographical sense of place, heritage, identity and ownership were clearly overwhelmingly strong. In the case of the Edinburgh Mela this has created a split in the board who believe that the Mela should remain a showcase for traditional rather than popular culture and who wish to use the Mela as a forum for renewing interest in, or indeed gaining the interest of, second generation Asians and in this way ensuring musical traditions are not lost as a 
consequence of a different way of life. Recent artists appearing at the Edinburgh Mela included in 2003 Shafquat Ali Khan from Pakistan whose concert featured Ghazals, Sufi, Punjabi Folk and fusion. Bollywood style singers and dancers were included as part of the overall program of events but were not intended to replace traditional and folk musical elements. Performance can work as a memory trigger and acts in this case as a link to other memories beyond the act of performance, such as traditional ways of life. ${ }^{32}$

As the artistic policy highlights, the Edinburgh Mela is also concerned with Scottish traditional culture and music and Mela 2002 featured major fusion events involving upwards of fifty musicians and singers from Scotland, China and Pakistan. They proved a tribute to poet Hamish Henderson - 'Roses Come to Bloom' - incorporating a fusion version of 'Freedom Cam A'Ye'. This concert was funded by trade union UNISON, the Performing Rights Foundation and the British Arts Council. This raises several points worthy of consideration. Is the inclusion of Scottish traditional music in Mela part of the process of acculturation, a reflection that Scottishness is part of the dual identity of Scotland's Asian Diaspora, or does it highlight the minority nature of such music within Scotland, where popular culture or high cultural art forms as exemplified by the International Festivals hold sway? Is this fusing of Scottish and traditional Asian music a way of fusing identities or is it keeping Scottish traditions - or a version of what is deemed to be Scottish traditions - alive in an increasingly changing society? If so this would reprise the point made earlier about identities becoming increasingly unstable in a fast changing society.

For Bauman 'recasting quite real individual frailties and infirmities into the imagined potency of community results in conservative ideology and exclusive pragmatics'. This may be relevant to the emphasis within the Edinburgh Mela on traditional South Asian and Scottish cultures with the added desire to create continuity, if not actively resist changing patterns of cultural and leisure activities. ${ }^{33}$ Dual or multiple identities, however, can create the potential for a deeper understanding of self. ${ }^{34}$ Diaches understood his relationship to being Scottish and Jewish in a way where both identities, forged within or between two worlds, allowed for a subjective and changing reappraisal of self which is prompted by the signifiers of each:

I found the sound of the bagpipes extremely moving. It awakened my sense of Scottish history with its violence and its pageantry and its fatal predilection for the lost cause... Scotland came for me more an emotion than a country. ${ }^{35}$

This perception of Scotland as a country which is both colonised and coloniser the main thrust of Hamish Henderson's 'Freedon Cam A'Ye' - creates a tension, sometimes seen as melancholy ${ }^{36}$ or as representing a culture of inferiority. ${ }^{37}$ This is often defined against the ruling neighbour, England. Indeed Scotland, by defining against what it is not, has created an imagined community ${ }^{38}$ that is 
forever England and English migrants at some ten per cent in the last census remain the largest single minority group in Scotland. ${ }^{39}$ Similar arguments are made about Scots migrants to England and although the scale of activity is less numerically it is often noted that many hold positions of power particularly in central Government. ${ }^{40}$ It is in this spirit of Diaches' definition of Scotland as an 'emotion more than a country' that the Edinburgh Mela has developed Scottishflavoured events which represent hybrid cultures of both worlds, drawing on the symbols of a largely imagined Scotland or definition of Scottishness to create a way for Scotland and its various communities to be defined and self-define creatively. It can be argued that Scottish Asians become acculturated into Scottish cultures and their dual identity develops as a Scottish Asian consciousness rather than an Asian/British one. ${ }^{41}$ The Edinburgh Mela is actively seeking to develop relationships within the Diaspora to ensure that Scottish Asians retain contact with the cultural expressions of South Asia and that Melas events represent these relationships through the creation of new performance pieces. As a consequence of these partnerships Edinburgh Mela trained personnel are, at the time of writing, going to Bangladesh to develop artworks with traditional artists and musicians which they will then bring back to appear at the Edinburgh and other Mela's within the UK.

\section{FUtURE OF THE EDINBURGH MELA}

In common with other Melas, the Edinburgh Mela is concerned with ensuring that it continues to celebrate the Asian Diaspora inclusively and with integrity and 'magic'. But it also aims to promote the Scottish connection and to grow and develop creative links within the Diaspora that will benefit both. The Edinburgh Mela also needs to encourage young people to participate in, and in some cases be willing to be trained to take on, an active role as future staff. Those who participate often do so to please their parents rather than from any belief that the Mela is expressing ideas about their own current or future sense of identity and values. Indeed television coverage ahead of the 2003 Mela concentrated on the role of the Mela in teaching young girls how to wear the sari and to experience the cultural and musical traditions of their mother's generation.

The Edinburgh Mela Youth Forum holds events throughout the year to establish links and funding is being sought through the Edinburgh Festivals Youth Development Fund to formalise these activities with the addition of a dedicated and safe year round space for young people to meet. Tweedie, however, observes that we have 'been told in Youth Forum by one young guy aged 18 or 19 [that]... "These folk wouldnae been seen fuckin' de'd at a Mela, because they think it is nothing to do with them." They are modern Scots'. ${ }^{42}$ Modern Scots might display similar attitudes to 'traditional' Scottish activities. Such generational conflicts are common amongst all cultures and are not easily resolved. This is one of the biggest challenges facing arts programers everywhere, not just Mela directors. 


\section{CONCLUSION}

The Edinburgh Mela, despite differences of opinion on the board, is determinedly avoiding the seeming pitfall of adopting a purely popular culture approach which would move the Mela from the community grounds it currently occupies into a mainstream space offering, for example, concerts for 30,000 people in Princess Street Gardens. It is now an established part of the summer festivals and organisers remain aspirational in their desire to see it grow in numbers and reputation. The Mela reflects hybrid, entangled cultures and to some extent creates a forum to explore ideas about Scottish cultural identity and being South Asian in Scotland. Tweedie acknowledges that is easier to grow tourist audiences, and this inevitably means growing a white middle-class audience, than it is to sustain and develop links with certain local audiences including South Asian Scots and local Scots who live within the geographical area where the Mela is currently cited, in particular and crucially with young audiences. There is a seeming irony that the more established and professional the Edinburgh Mela becomes the less likely it is to remain at the community level. This is already apparent in recent activities. Whilst they genuinely reflect the wider Asian Diaspoa events are in many cases ticketed rather than free to all visitors. The future of the Mela in this form is only ensured if the organisers succeed in developing year round activities which can reinforce the sense of community ownership of, and participation in, the festival across the generations.

\section{Endnotes}

1 R. Ferguson, Representing 'Race': Ideology, Identity and the Media, Arnold, London, 1998.

2 The Parekh Report, The Future of Multi-Ethnic Britain, Profile Books, London, 2000.

3 J. Weeks, Making Sexual History, Polity, London, 2000, p240.

4 S. Flusty, De-Coca-Colonization: Making the Globe from the Inside Out, Routledge, London, 2004, p112.

5 G. Baumann, Contesting Culture: Discourses of identity in multi-ethnic London, Cambridge University Press , Cambridge, 1996.

6 A. Brah, Cartographies of diasporas: Contesting identities, Routledge, London, 1996, p18.

7 Z. Bauman, Community: Seeking Safety in an Insecure World, Polity, London, 2000.

$8 \mathrm{~L}$. Back, New Ethnicities and Urban Culture: racisms and multiculture in young lives, UCL Press, London, 1996.

9 Baumann, op cit.

10 ibid.

11 ibid.

12 V. Chaudhary, 'The big bhangra', The Guardian, 15 August 2003, online.

13 D. Morley, Home Territories: Media, Mobility and Identity, Routledge, London, 2000.

14 N. Khan, The Arts Britain Ignores: The Arts of Ethnic Minorities in Britain, London, Commission for Racial Equality, 1976.

15 M. Carlson, Performance: a critical introduction, Routledge, London, 1996.

16 R. Candida-Smith (ed), Art and the Performance of Memory: Sounds and Gestures of Recollection, Routledge, London, 2002

17 R. Kaur and J. Hutnyk, Travel Worlds: Journeys in Contemporary Cultural Politics, Zed Books, London, 1999.

$18 \mathrm{H}$. Jermyn and P. Desai, Arts - what's in a word?: ethnic minorities and the Arts, Arts Council of England, London, 2000.

19 J. Mowitt, 'In the Wake of Eurocentrism: An Introduction', Cultural Critique, no 47, Winter, 2001, p8.

20 L. Lippard, Mixed Blessings: New Art in a Multicultural America, Pantheon Books, New York, 1990.

$21 \mathrm{~J}$. Errol, 'Mama look a Mas' in Masquerading: The Art of the Notting Hill Carnival, Arts Council of Great Britain, London, 1986.

22 P. T. Alleyne-Dettmers, Carnival: the Historical Legacy, Arts Council of England, London, 1996.

23 Interview with Alan Tweedie, Chief Executive of the Edinburgh Mela, 21 April 2004.

24 ibid. 
25 ibid.

26 ibid.

27 ibid.

28 Interview with Lynne Halfpenny, Edinburgh City Council, 10 October 2002.

29 Edinburgh Mela Artistic Policy Document, 2003.

30 Mowitt, op cit.

31 Interview with Alan Tweedie, 21 April 2004.

32 Candida-Smith, op cit.

33 Z. Bauman, Community: Seeking Safety in an Insecure World, Polity, London, 2000, p100.

34 B. Moustafa and R. Andrew, The Said Reader, Granta, London, 2001.

35 D. Daiches, Two Worlds, Canongate Classics, Edinburgh, 1957, p59.

36 M. Watson, Being English in Scotland, Edinburgh University Press, Edinburgh, 2003.

$37 \mathrm{C}$. Beveridge and R. Turnbull, The Eclipse of Scottish Culture: Inferiorism and the Intellectuals,

Edinburgh University Press, Edinburgh, 1989.

38 B. Anderson, Imagined Communities: Reflections on the Origins and Spread of Nationalism, Verso, London, 1992.

39 Watson, op cit.

40 D. Stenhouse, On the Make: How the Scots Took Over London, Mainstream, Edinburgh, 2004.

41 B. Mann, The New Scots, John Donald, London, 1992.

42 Interview with Alan Tweedie. 